\title{
Foreword
}

\section{Improving Perioperative Care: What Are the Tools That Lead to Sustainable Change?}

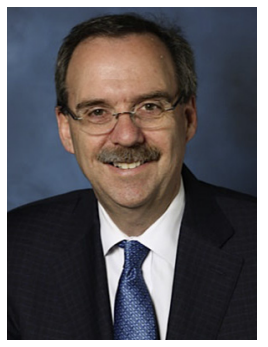

Lee A. Fleisher, MD, FACC, FAHA Consulting Editor

The future of anesthesiology lies in our specialty's engagement in improving all aspects of perioperative care for the patient. While some have advocated the concept of the Perioperative Surgical Home, others have focused on perioperative medicine. The hallmark of either concept is change management and the ability to make the process culturally sensitive and that they "stick." Quality improvement is a formal approach to the analysis of performance and systematic efforts to improve it. Implementation Science is the study of methods to promote the integration of research findings and evidence into health care policy and practice. Together, they offer us the tools to provide high-quality care in a local environment.

This issue was edited by Meghan Lane-Fall, MD, MSHP and me. Dr Lane-Fall is currently Assistant Professor of Anesthesiology and Critical Care at the Perelman School of Medicine at the University of Pennsylvania. Her current research focuses on the impact of teamwork and communication on health care quality in the perioperative and critical care settings. Dr Lane-Fall has expertise in the use of mixed methods to answer health services research questions related to surgical care and critical illness. We have brought together a phenomenal group of authors to educate us on best current practices.

Lee A. Fleisher, MD, FACC, FAHA Department of Anesthesiology and Critical Care Perelman School of Medicine Health System University of Pennsylvania 3400 Spruce Street, Dulles 680

Philadelphia, PA 19104, USA

E-mail address:

Lee.Fleisher@uphs.upenn.edu 